\title{
Ahead of time in features, ergonomics and availability
}

Not only have Planmeca dental chairs got all the features you want, but they are also ahead of time in availability. Place an order today and you can expect your brand new chair to be delivered to your distributor in only nine weeks. Why wait when you can make the change today?

There is a choice of versatile dental chairs including the Planmeca Compact i5,

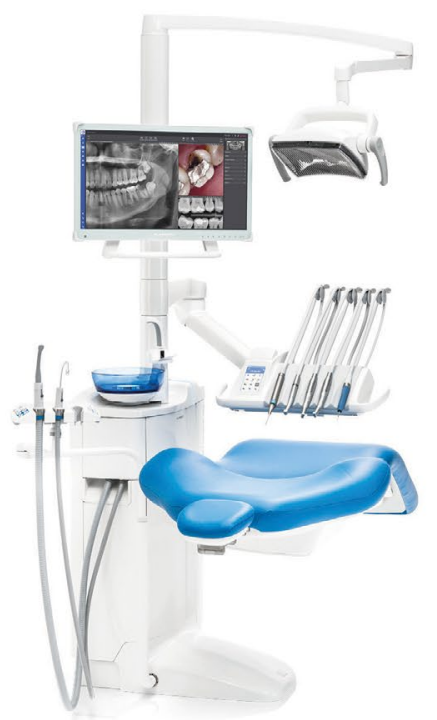

designed to offer the smoothest possible workflow and stress-free dentistry. They are both sleek and elegant, whilst also allowing you to maintain an optimal ergonomic working position throughout the day.

The Planmeca Compact i Classic presents ease of use and uncompromised ergonomics in a cost-effective dental unit, making it an ideal choice for general dentistry.

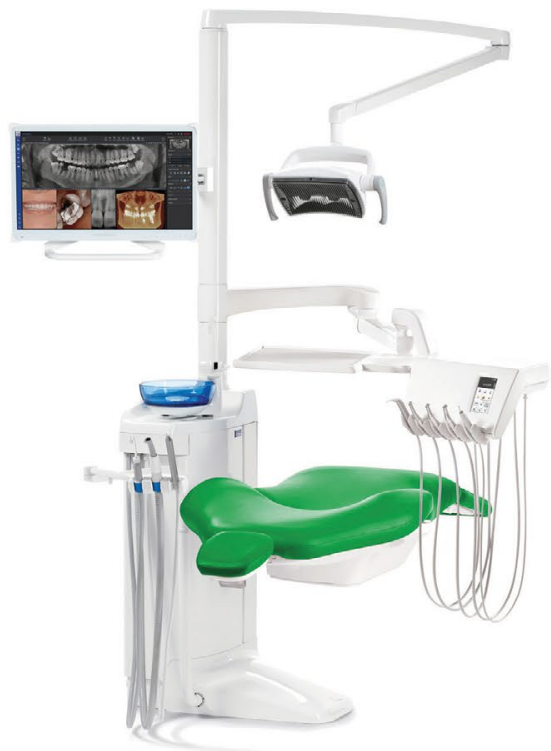

\section{Dental training roadshow goes on national tour}

Dr Robbie Hughes, cosmetic dentist and owner of Dental Excellence in Liverpool, is taking his Digital Composite Veneers Course on a tour of the country, bringing his innovative injection mould technique and training to more dentists.

Dr Hughes is responsible for designing some of football's greatest smiles and will be offering his new one-day composite injection mould training at football stadiums nationwide from January 2022.

The course will be open to dentists and dental therapists looking to offer their clients first-class composite veneers treatments using the injection mould technique, through a pioneering digital dentistry workflow. It will be a hands-on practical training day, with delegates learning the physical process, as well as data acquisition, data processing, lab communication and a full Q\&A. The training promises to help dentists create stunning and accurate smiles, even in the most complex restorative cases, where predictability and quality are guaranteed.

Dr Hughes invests heavily into training his peers; this training is helping to transform the cosmetic dentistry landscape to be more efficient, more precise and more cost-effective for customers.

Dr Hughes is joined by Dr Milad Shadrooh, the nation's favourite 'Singing Dentist', and both are particularly passionate about shaping the future of digital dentistry and nurturing the next generation of young, talented clinicians as they learn and progress.

The elite professionals that take part in Avant Garde training are at the forefront of cosmetic dentistry in the UK and Ireland and are pioneers in their respective fields. Between Dr Hughes, Dr Shadrooh and the rest of the training team, delegates will spend the day learning from some leading experts in cosmetic dentistry and will leave with a much-coveted new skill.

The fixtures for the training include the
And finally, the Planmeca Compact $\mathrm{i} 3$ is small, swift and clever, designed to simplify everyday dentistry with easy-to-use external infection control procedures. It's the practical choice - a true space saver.

For more information on Planmeca dental chairs and those exceptional lead times, email marketinguk@planmeca.com, call 0800 5200330 or visit www.plandemo.co.uk.

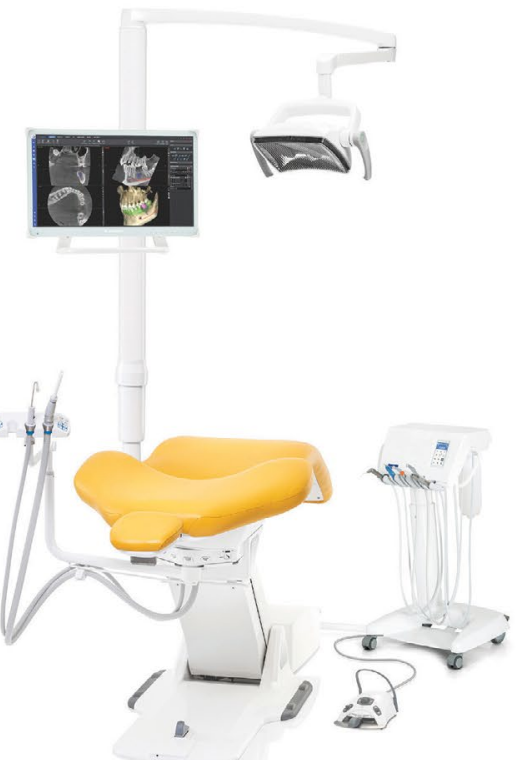

following stadiums during 2022, with one course taking place per month: Stamford Bridge (London), Villa Park (Birmingham), Etihad Stadium (Manchester), Aviva Stadium (Dublin), Cardiff City Stadium (Cardiff), Tottenham Hotspur Stadium (London), Tynecastle Park (Edinburgh), Elland Road (Leeds), Emirates Stadium (London), Old Trafford (Manchester), London Stadium (London), Wembley (London).

The course costs $£ 599$ per delegate but is reduced to $£ 399$ if booked before the end of 2021. To book a place on the course or to find out more about the Avant Garde training services visit: www. avantgardedentistry.co.uk.

Avant Garde Dentistry are pleased to offer one $B D J$ reader a free place on their course. The first person to email k.quinlan@nature.com quoting the word AVANT COMPETITION by 6 December 2021 will be the lucky winner. 